\title{
Citizenship Education and Liberalism: A State of the Debate Analysis 1990-2010
}

\author{
Christian Fernández • Mikael Sundström
}

Published online: 4 March 2011

(C) The Author(s) 2011. This article is published with open access at Springerlink.com

\begin{abstract}
What kind of citizenship education, if any, should schools in liberal societies promote? And what ends is such education supposed to serve? Over the last decades a respectable body of literature has emerged to address these and related issues. In this state of the debate analysis we examine a sample of journal articles dealing with these very issues spanning a twenty-year period with the aim to analyse debate patterns and developments in the research field. We first carry out a qualitative analysis where we design a two-dimensional theoretical framework in order to systematise the various liberal debate positions, and make us able to study their justifications, internal tensions and engagements with other positions. In the ensuing quantitative leg of the study we carry out a quantitative bibliometric analysis where we weigh the importance of specific scholars. We finally discuss possible merits and flaws in the research field, as evidenced in and by the analysis.
\end{abstract}

Keywords Citizenship education - Liberalism - State of the debate $\cdot$ Thick and thin

\section{Introduction}

What kind of citizenship education, if any, should schools in liberal societies promote? And what ends is such education supposed to serve? Over the last decades a respectable body of literature has emerged to address these and related issues. The reasons for the swelling scholarly and political interest are many. First, globalisation and internationalisation has necessitated efforts to prepare citizens-in-spe for a world that is more interdependent, culturally diverse and mobile than ever. We thus confront claims that children need to be taught "cardinal virtues" of such a world. Second, large-scale migration and

C. Fernández ( $ه)$

Malmö Institute for Studies of Migration, Diversity and Welfare (MIM), Malmö University, 20506 Malmö, Sweden

e-mail: christian.fernandez@mah.se

M. Sundström

Department of Political Science, Lund University, Box 52, 22100 Lund, Sweden

e-mail: mikael.sundstrom@svet.lu.se 
increasing societal diversity provide an impetus to locate and define the elements that bind us together as a society-and to promote, even implant, those elements in rising generations. This is reflected in educational reforms enacted by several European countries, where norms and values that citizens are supposed to endorse are explicitly defined.

Citizenship education is particularly challenging and interesting from a liberal perspective, we argue, because it is so divisive and fraught with tensions (cf. Galston 1991, p. 248). Citizenship education implies the shaping and tempering of children in certain ways that will turn them into good citizens. It presupposes a shared conception of what a good citizen is, the special qualities and virtues that distinguish him and her, and the methods that should be employed to educate such citizens. These is a difficult and controversial question from any viewpoint, but especially so from a liberal perspective because the liberal ideology is defined by its opposition to the "micromanagement" of individuals. Liberalism is animated by the conviction that individuals are capable of knowing and deciding for themselves what a good and meaningful life is. The personal qualities and virtues that help build such a life are private and should consequently be outside the remit of the state or any other authority. In order to avoid, or at least reduce, collisions between the private morality of individuals and the public morality of the citizenry, the latter should be formulated as neutrally and minimally as possible. Thus the common liberal insistence on the value neutrality of the state.

The inherent divisive tensions of liberal citizenship education have given rise to a rich and diverse academic discourse. "Diverse" is the keyword here, as it provides the central drive behind this article. It is basically very difficult to get a comprehensive picture of the academic advancements in the area, and attempts to unravel central themes are weighed down by the sheer scale and diversity of material on offer. The overarching aim of this article, then, is to systematise and evaluate/discuss some of this diversity by describing and explaining certain general traits of the academic debate. We carry out a study where we make a cross-sectional analysis (see more section "Study Design") of a wide range of scholarly journals spanning 20 years, sounding the material for debates that touch the intersection between liberalism as an ideology and the rôle and potential of the education system as a fostering agent. To aid us in this process, and make the results more approachable, we devise an analytical framework that extracts two specific liberal discourse dimensions. Parsed results will, somewhat simplified, be mapped onto a twodimensional representation, whereupon clusters or notable aberrations will be highlighted and appraised.

Much simplified, in this state of the debate analysis we aim to:

- Map the potential reach of the discourse. We develop an analytical framework that serves to map and explain liberal positions with respect to civic education. The framework is not specifically bound to this study but should be usable elsewhere too.

- Study the actual reach of the discourse. Our model maps the potential reach of the discourse, but what does the actual discourse look like? By running the material through the analytical framework we see how the actual reach of the discourse compares to its potential reach.

- Identify discourse patterns. The analytical framework helps us identify and sort key issues, internal tensions, controversies and points of convergence, and provides an opportunity to spot broader patterns in the material.

- Identify internal and external discourse constraints. Aided by a bibliometric study, we finally discuss some factors that appear to shape the reach and patterns of the discourse in the studied material. 
We wish to emphasise that our aim is not to summarise the findings of the research field or assess their validity (cf. Oakley et al. 2005). Rather, our main objective is to improve the understanding of what a contemporary liberal take on citizenship education can imply, with a particular focus on standpoints and justifications, major debate tensions and prevalent themes.

\section{Study Design}

The design of the study will determine the organisation of the text, and will demand some preparatory remarks to highlight key methodological considerations and (self-imposed) constraints and delimitations. Figure 1 (below) outlines what we have in mind.

Each of the bullets (1-4), plus the design of the analytical framework itself, represent elements that will duly be discussed-material selection issues in this section, other parts later.

\section{Material Selection}

Citizenship education, and the philosophical ideals that should govern it—or not-is a thematic area that presents researchers with many thorny methodological problems. Its very sprawl is daunting, as this is where many academic disciplines converge. Political philosophy, pedagogy, sociology, psychology (and more) — all offer viable research vectors to be considered. In short, researchers-like us-aiming to carry out a broad literary study face an over-abundance of texts, placed in a surprising variety of journals and other repositories. Where we should look, or rather how we should look, for relevant material becomes a primary concern.

For reasons elaborated below, we have opted against manually selecting candidate journals to proceed with. Instead the first-order sorting procedure is a full-text search of a database, the "Electronic Library Information Navigator" (ELIN), which in turn collates

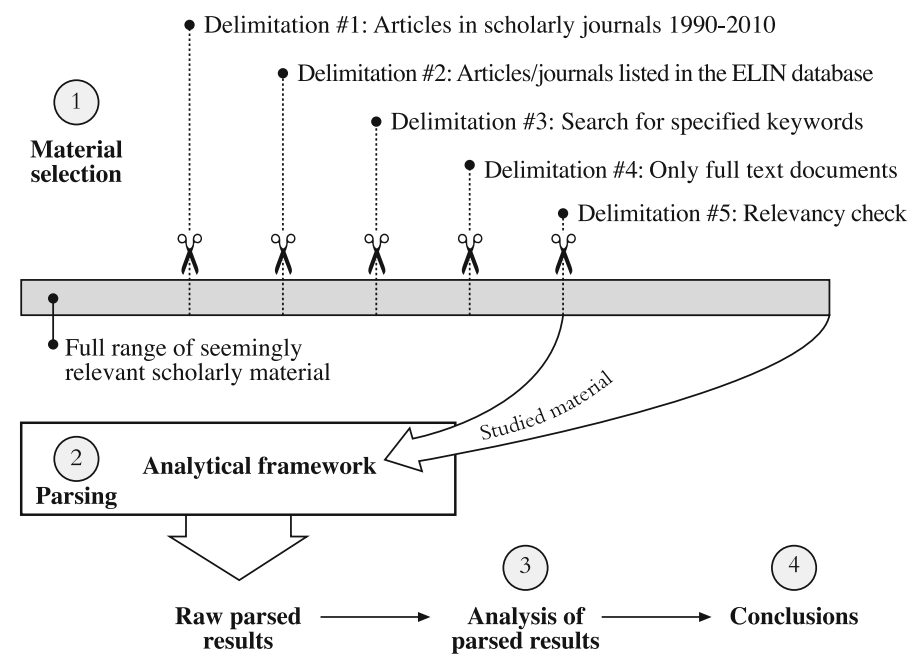

Fig. 1 Study mechanics - an overview 
information from a substantial number of premier databases of academic journals and other material. The collected material is based on the following search criteria (on any and all fields, i.e., including full body text):

- "Liberalism and Political Education"

- "Liberalism and Citizenship Education"

- "Liberalism and Civic Education"

From the resulting subset we have removed non-articles, and articles not available in full text. We have additionally removed material before 1990 on the assumption that only a select few journals have on-line archives going back further than that.

The final "relevancy check" (\#5 in the figure above) includes the following:

- We remove material where we feel located material is wholly incidental to the matter in hand.

- We only review articles that deal with or touch upon the normative, philosophical aspect of liberal citizenship education. Descriptive empirical studies that lack any philosophical preamble are not included.

- We only review authors who write from within a liberal standpoint and/or try to resolve the liberal problem of citizenship education.

- We only review full text articles written in English.

Unavoidably, our adopted methodology is not "perfect", as the various selection decisions are all open to challenge. We believe that the stated delimitations are both sound and necessary given the purpose and scope of the study - and we have made a conscious effort to make them transparent in order to expedite any ensuing discourse on related concerns.

First, we fully realise that, as the ELIN database does not include all academic journals, we risk overlooking relevant articles. However, we think that it is preferable to rely on a single, rich, and general collation engine, and to avoid complementing trawling methods at the initial stage of material gathering. If there is a bias, it is at least mechanical, and not a consequence of, say, mismatching trawling methodologies. ELIN is additionally, and by some distance, the richest database we had access to-which should minimise if not eliminate the problem of excluded data.

Second, our automated trawling method is less reliable than would be a manual selection process - after all, potentially relevant articles that fail to match any of our search criteria will escape us unnoticed. On the other hand, automation has enabled us to scan a material many times larger and more diverse than we could ever have hoped to had we attempted to do it manually.

Third, our method of selection excludes books and other potentially influential nonelectronic publications. However, as research findings tend to be published and debated in journals before (sometimes) being turned into monographs or anthologies, we consider the exclusion of books a reasonable delimitation for a state of the debate analysis.

Fourth, the study covers the years 1990-2010, even though we are fully aware that the debate on citizenship education and liberalism goes much further back. Our focus is the contemporary state of the debate and we believe that two decades' worth of material should be sufficient-not to mention the fact that our database-dependent method of selection would falter should we attempt to include older material. Indeed, the distribution of hits (Fig. 2) suggests that even the early 1990s may be a problem in this respect. We think that this deficiency is tolerable, given that our study is not primarily a 


\section{Journal hits (journal name + number of located articles)}

American Journal of Education (1)

British Journal of Educational Studies (1)

British Journal of Political Science (1)

Canadian Journal of Political Science (1)

Childhood (Copenhagen) (1)

Educational Philosophy and Theory (1)

Educational Studies (1)

Educational Theory (2)

Ethics (4)

International Journal of Educational Research (1)

International Studies in Sociology of Education (1)

Irish Political Studies (1)

Journal of Applied Philosophy (1)

Journal of Philosophy of Education (9)

Journal of Political Ideologies (1)

Journal of Social Philosophy (1)

New Blackfriars (1)
Oxford Review of Education (1)

Perspectives on Political Science (1)

Political Quarterly (1)

Political Studies (1)

Political Theory (2)

Polity (1)

Review of Politics (2)

Social Theory and Practice (2)

Studies in Philosophy and Education (11)

The American Political Science Review (1)

The Review of Politics (1)

Theory and Research in Education (2)

\footnotetext{
* Four out of these eleven pieces belong to the same thematic issue focusing on a book symposium about Harry Brighouse's book School Choice and Social Justice (Brighouse: 2002).
}

\section{Article Distribution on the 1990-2010 Timeline (55 Articles).}

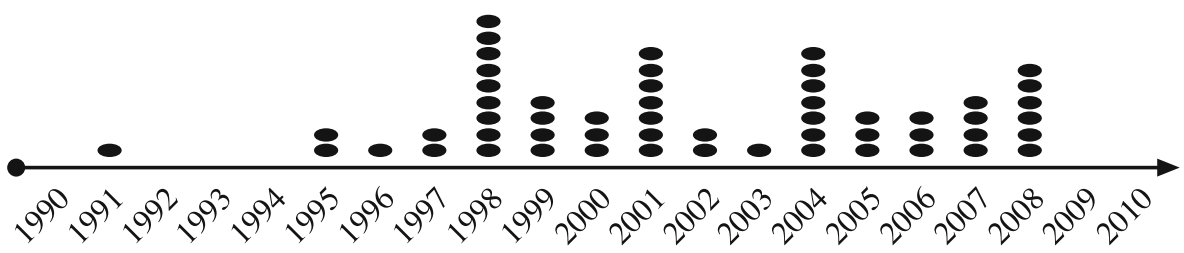

Fig. 2 Located articles: an overview

longitudinal one, and that 15 years of data would still amply cover what we consider the "contemporary". 1

Finally, we ended up with 55 online articles written in English; a sample that we believe is quite representative of the contemporary scholarly debate in the West. It might be argued that this sample is too small, and that, we should therefore have reconsidered the selection methodology, with a view to re-casting it to make it open to the acceptance of more articles. The problem, of course, is that even a sample twice as big would leave us open to exactly the same criticism, while alterations to the selection mechanism have (to us undesirable) repercussions for the scope of the study too.

Study Aim: Citizenship Education, a Conceptual Map

Citizenship education is sometimes formalised in individual subjects called civics or something equivalent, but it is clearly a mainstay in other parts of the curriculum as well,

\footnotetext{
${ }^{1}$ For the record, the lack of 2009 and 2010 hits will perforce to some extent depend on publishing technicalities, e.g., volume year/actual publishing year mismatch; legal issues (such as delayed volume availability in electronic depositories); database update and propagation processes and the like.
} 
e.g., history, social science, and world religions. The distinguishing feature is the approach (and what follows from it) rather than the label of the subject and its formalised content. One such approach is the objective teaching of "facts" about the history of a country, its political system and ethnographic composition. Another is the inculcation of values such as democracy, human rights and respect for the environment. A third is the honing of intellectual skills and qualities such as critical reason, scepticism and open-mindedness. These approaches are all part of the concept, although different scholars place emphasis on different parts. Our aim is to explore academic takes on citizenship education, and what it can and should be-according to the scholars in question. We thus have little need for a rigorous definition of citizen education-indeed given our aim, a pre-determined definition might effectively put on us undesirable analytical blinkers.

Because of the broad canvas of possible "liberal" interpretations, we have found it helpful to establish a classification schema where liberal takes are positioned as based on specified standpoints (which will be detailed below). The resulting set of archetypal "positions" will help us manage a highly complex material by initially discarding the finely drawn, but also distracting, details in order to focus on broader thematic brushstrokes. The relatively small number of archetypal positions makes us better able to examine intrinsic tensions between different "liberalism-derivative" justifications, and explore how such derivatives might be turned into schooling practice before we turn to the actual material.

The Analytical Framework and the Studied Articles

The analytical framework we design will be used to parse the located texts, but will not be contingent on them. This is because we do not wish the articles to define the initial space of possibilities, as that may well engender an analytical circularity problem. With this in mind, we use a separate and carefully selected literature to establish the reach of the conceptual map. This means that when we parse the articles we will not only be comparing them against each other as it were, but will also have independent pre-established benchmarks by which to evaluate them.

This is not to say that the framework is final and unalterable, however. We evolve it to the point where we think it is solid and readily usable, lock down this state, and finally proceed to use it. Though we lack space to do it here, it would be quite feasible to revisit the design of the framework with the aim to use relevant parsed material, or indeed other complementing sources, to upgrade it in preparation of future analyses.

\section{Thick and Thin Liberalism: An Analytical Framework}

\section{Appraising Liberal Takes on Schooling: A Two-Dimensional Approach}

The thin-thick continuum refers to the substance of citizenship education. The two terms should not be thought of as synonymous with strong and weak ideas of education since both can be grounded in very strong principles about the legitimate aims of liberal education. Nor should they be thought of as evaluative or prescriptive on our behalf-we use them only for classification purposes. In the following we will distinguish between two such dimensions of thick and thin. 
The Ethical Dimension

The question of thick or thin is on the one hand a question of ethical density (cf. Paris, p. 891). How much in terms of values and norms should be ingrained in citizenship education? The potential answers can be conceptualised as a sliding scale from the thick, ethically dense education that trains young boys and girls to become citizens of a certain (good) kind to the thin, non-ethical education that reduces preparation for citizenship to morally neutral knowledge of the home country and the world. The first position is one where schools seek to inculcate certain virtues in children, such as patriotism, solidarity, loyalty, piety, empathy, care, and so on. The second position is one where schools are neutral in such ethical matters and civic education is focused on "objective civics" such as history, social science and perhaps world religions (though that would be more controversial). The thick position is often justified as a means to reproduce and refine a system of values and/or culture that may otherwise deteriorate over time. The thin position, on the other hand, is often formulated as a critique of the thick position, where the argument is that moral indoctrination is not a legitimate part of schooling. We will label this scale from thick to thin the ethical dimension of citizenship education.

\section{The Public Dimension}

The question of thick or thin is also a question of state control of, and involvement, in schooling. Namely, to what extent should the content of citizenship education reflect the core ideals and ideas of the (liberal) state? We can conceptualise this dimension as a sliding scale from state paternalism where public control is high to private parentalism where it is low. ${ }^{2}$ The first position is one where education aims to create (in our case) liberal citizens prepared for a life in liberal democratic societies, whether it be through an ethically thin or thick education. The second position is one where education is minimally liberal, giving parents and other private stakeholders much more control over citizenship education, which makes for more diversity and freedom of choice. The state paternalist position is often justified with egalitarian arguments, e.g., that the state has a responsibility to provide all children with equal opportunities in life and an obligation to promote political unity and integration. The private parentalist position is typically justified by stressing the special rôle of the family and the accompanying responsibility parents have vis-à-vis their children-as well as by references to more generalised private freedom of individuals, families and groups. Proponents are usually appreciative of a diverse school system and regard with suspicion all attempts by the state to cast all schools in the same mould. We will label this span from thick to thin the public dimension of citizenship education.

\section{Archetypal Positions in the Analytical Schema}

Put together the two dimensions are useful when we wish to categorise and explain different liberal standpoints on citizenship education. As we see below (Fig. 3), they may be conceptualised as forming a two-dimensional matrix within which any position can be justified on liberal grounds. One aim of this article is to detail how different matrix

\footnotetext{
${ }^{2}$ In many cases, discussions about freeing up the schooling format itself (i.e., introducing schools run by entities other than the state), or not, will coincide with this dimension, but it is (for example) still possible to discuss a thin public dimension that is realised within a state schooling format.
} 
Multiculturalism: Diversity, cultural survival and group autonomy are key words in the multicultural position. It is ethically thick insofar as it seeks to foster and preserve the virtues and beliefs of different groups through a diverse school system. It is publicly thin insofar as it opposes state interventionism and attempts to homogenise the school system.

Market liberalism: Freedom of choice, private supply and competition are key words in the market position. It is ethically thin insofar as it emphasises formal knowledge and professional success as the sole ends of education. It is publicly thin insofar as it favors private schools on a competitive market over a public school system.

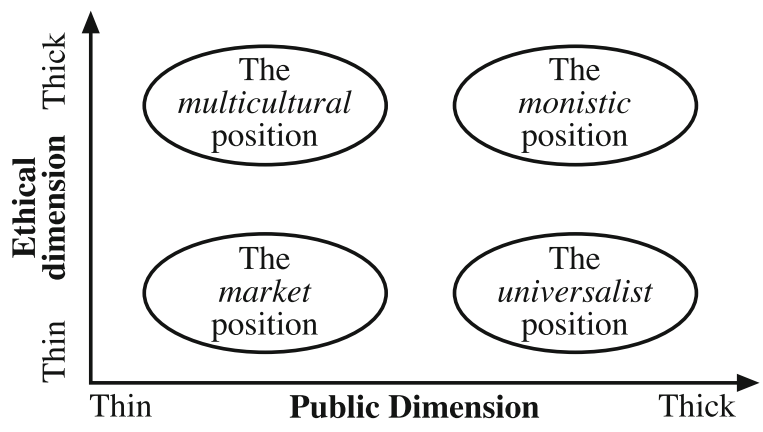

Monism: Unity, equality and common citizenship are key words in the monistic position. It is ethically thick insofar as it seeks to foster and renew the virtues and ideals of the democratric liberal state through common schools. It is publicly thick insofar as it places the prime responsiblity for the reproduction of such education in the hands of the state.
Universalism: Liberation, indivual freedom and universal rights are key words in the universalist position. It is ethically thin insofar as it defends only the non-negotiable values of a liberal order. It is publicly thick insofar as that order is protected by a state that, if necessary, has the right to use schooling to liberate children from anti-liberal groups and parents.

Fig. 3 Archetypal liberal positions in the analytical schema

standpoints tend to be justified in actual scholarly material and what they-more concretely-have to say about citizenship education. To simplify matters we select four archetypal extremes in the matrix that we flesh out, and then relate the material to.

\section{Parsing the Articles}

When we process an article, we begin by determining its "home" in our schema, as based on the two analytical dimensions. To position a piece along each dimension we first weigh explicit definitions and justifications of central concepts and values. Thick ethics, for example, might be "recognised" by the promotion of allegedly individual and neutral values that are equally valid to all citizens regardless of race, religion, sex and other quiddities. Evident criticism of private schooling unfettered by state curriculum demands would similarly provide strong indication that the text leans towards the thick end of the public dimension. In many cases authors (for some reason not caring that they would one day make life harder for surveyists) are less obliging, and join an on-going discourse with little preamble. In such cases we need to triangulate their dimensional positions using their identified sparring partners — whether allies or adversaries—as markers.

We next proceed to study to what extent the effort in hand joins an "intra-positional" discourse. When we aggregate data, this will tell us something about the scholarly dynamics within that position-is debate on-going and active or is the position, relatively speaking, more inert? 
We then analyse how the author relates to the three remaining archetypal positions in the schema (non-engagement will also be duly noted). Again, we are primarily after aggregated results - this way we can see broad "engagement patterns" which will never be evident in individual efforts.

We finally note if there are any significant "others" - theoretical takes with which the author engages, but which fall outside the identified positions in the schema. To the extent that we find patterns here, these will be duly discussed when we sum up the parsing effort.

\section{The Multicultural Position}

$[\mathrm{W}]$ hat we need $[\ldots]$ is an account of liberalism that gives diversity its due. This understanding is expressed in what I shall call the "Diversity State"-that is, in public principles, institutions, and practices that afford maximum feasible space for the enactment of individual and group differences, constrained only by the requirements of liberal social unity (Galston 1995, p. 524).

\section{General Overview of Articles and Themes}

Over the last decades, multiculturalism has provided an influential strand of liberal educational philosophy. Although not strongly represented in our material, it is present in terms of the counter-reactions it provokes from other liberal camps. Viewed thus, it is fair to say that multiculturalists have been successful agenda-setters for the liberal debate on schooling.

The multicultural position rests on two main premises. The first is that culture is essential to human wellbeing and a precondition for many values and ends that liberals hold dear. Cultures bestow a sense of meaning and purpose, and a context where our strongest aspirations, beliefs and commitments can develop and thrive. The second premise is that many minorities live under a constant threat of assimilation and cultural deracination, surrounded, as they are, by people and public institutions of the mainstream culture. If cultural attachment is essential to human wellbeing, it follows that protection of "endangered" cultures must be a key liberal concern (see Galston 1995; Pybas 2004; White 2003).

To the multiculturalist, then, schooling in general, and civic education in particular, is a matter of cultural survival. The threat of losing one's culture is especially salient in schools, because schools are instruments of cultural reproduction and children are by their very nature especially amenable. Philosophers attached to the multicultural quadrant uniformly share the conviction that civic education is an important aspect of schooling. It must be ethically thick in order to resist the assimilative pressures of mainstream culture and, for the same reason, publicly thin.

\section{Intra-Positional Engagement}

Key Issues A high-profile question engaging multiculturalists is confessional schools, i.e., schools where students share the same faith and where civic education is partially derived from religious doctrine. Such schools are controversial because they are often perceived as breeding grounds for intolerance and religious fundamentalism. On the other hand, defenders claim that they provide necessary havens for groups otherwise struggling to hold on to their faith-based ways of life. To Linda White (2003), for example, the most compelling argument in favour of such schools is the overriding "right to culture", i.e., that individuals have a right to have their congenital culture protected (an argument she 
borrows from Margalit and Halbertal 1994). She argues that this right brings with it an obligation by the state not just to allow, but actively to promote the establishing of schools that enable local-cultural reproduction. This in turn requires state funding arrangements to support confessional schools. It also implies, however, that the state has a right to demand, indeed ought to demand, that religiously grounded civic education be balanced with a liberally grounded ditto that stresses crucial liberal values such as tolerance and mutual respect (cf. Galston 1991, ch. 11).

A more radical defence of religious schooling and variegated educational systems in general is provided by Pybas (2004). In a piercing critique of what he labels "Unitarian liberals", he advances both empirical and normative arguments supporting maximum diversity. Social diversity is a fact of life in pluralist societies like the United States and there is no evidence, he claims, suggesting that children in religious minorities and confessional schools grow up to be less tolerant than children in mainstream society. In a Tocquevillian spirit he argues that profound religious and other cultural passions are assets in a vibrant civil society-assets that may in fact serve to "restrain the less desirable tendencies of democratic society" (22).

Internal Tensions The question of personal autonomy versus diversity cuts right through the quadrant. Some philosophers, such as Will Kymlicka (1995), ultimately rely on the mutual reinforcement of culture and personal autonomy when they defend the notion of cultural protection. To Kymlicka, cultures are contexts that furnish individuals with genuinely meaningful alternatives to choose between. Others stress the tension between the two, yet refuse to make the value of culture contingent on the value of autonomy. Thus, to the latter, diversity is a value in and of itself (see Galston 1995). Defenders of autonomy typically want to limit religious and other forms of indoctrination so as to enable other qualities like personal choice and knowledge of the external world. Defenders of deep diversity, on the other hand, advocate maximum freedom for parents and communities to "raise their children in a manner consistent with their deepest commitments" (Galston cited in Pybas 2004, p. 28). To defenders of autonomy, minorities need to be internally liberal (in terms of individual rights and so on). To defenders of diversity, minorities need only be "compatible" with an external liberal society. Both Galston (1995) and White (2003) criticise Kymlicka's emphasis on autonomy, whereas the later John Rawls's softened standpoint on autonomy has inspired several liberals to attempt to accommodate claims for cultural protection within a liberal framework (e.g., Dagovitz 2004).

\section{Inter-Positional Engagement}

Despite its internal tensions, multiculturalism stands in marked distinction to monism and universalism. The monistic "unitarian" bent is regarded as overly repressive and discriminatory against minorities, and monists are thought to overstate the need for common institutions and state interventionism. The neutralist individualism of universalism is considered naïve at best; a false pretence for assimilation at worst. In practice it amounts more or less to the same thing as monism, some argue (see White 2003).

\section{The Market Position}

[T]he family remains, as long as it is denied political power, the best liberal hope for achieving true autonomy and diversity. That it, and not the state, retains final authority to 
exercise choice over the direction and content over the child's education (as long as that guidance is "reasonable" in the broadest sense) is both the true liberal principle and the best defence of the autonomy and pluralism that are liberal democracy's pride (Ruderman and Godwin 2000, p. 529).

\section{General Overview of Articles and Themes}

Market liberalism is a position defined by a fundamental belief in the market's ability to meet demands in a more cost-efficient manner, and with better end results than the stateplanned alternative. Competition between suppliers of public services increases quality and pushes prices down. These convictions are combined with a principled defence of private freedom and the minimalist state. More specifically, freedom of choice is the liberty that market liberals seek to maximise for the "customers" and "consumers" of society.

Viewed that way, civic education becomes something of a trifle. The distinction between education for work, business and citizenship virtually evaporates since all of them are defined by their market and/or private function. The position is often defended on functionalist and pragmatic grounds in conjunction with the following two assumptions: (1) the purpose of education is to produce competent and competitive students, and (2) public schools have been dismal failures in this regard-more dropouts, lower test results, soaring illiteracy rates, and so on (cf. Chubb and Moe 1990). Civic education is ethically thin because market functionalism prevails, and publicly thin because the state is deeply mistrusted.

There is also a more normative and principled line of defence, however, where the argument is that parents have an absolute right to decide where their children should go to school. This is an idea that seems to be gaining momentum in the United States where parentalists argue that the first amendment (freedom of expression) grants them the right to decide what beliefs, ideas and lifestyles their children should be exposed to. The stronger the focus on this claim, the more the proponents seem to have in common with hard-line multiculturalists (see Macedo 2000, pp. 21-23).

For whatever reason, our material includes but a single market position promoter, although certain studied articles use it as an "opposing other". The lack of more overt champions presents an interesting puzzle, given that the views expressed above are prevalent enough among policy-makers in most Western countries. Reasons for this discrepancy may include, but not be limited to, one or more of the following: (1) market liberalism is simply not a common position among philosophers; (2) market liberalism is predominantly empirical (and implicitly normative) and is thus seldom expressed in terms of norms, (anti-)civics or citizenship, and will thus escape our trawling methodology; (3) market liberalism is seldom described and defended as a form of liberalism at all, but as an integral feature of some other form of ideology (although this seems less than likely).

\section{The Monistic Position}

A democratic theory of education focuses on what might be called 'conscious social reproduction'- the ways in which citizens are and should be empowered to influence the education that in turn shapes the political values, attitudes, and modes of behavior of future citizens (Gutmann 1999, p. 14). 


\section{General Overview of Articles and Themes}

Monism stresses the common, unifying elements of society and grants political authorities a key rôle in the reproduction of these commonalities. Thus our choice of the monism label. It is influenced by Classical political philosophy and appears to have gained momentum by a reinvigorated general interest in Classical republican questions relating to citizenship, virtues and participation (see Pettit 1997; Dagger 1997; van Gunsteren 1998). In educational philosophy, the renewal appears especially influential and relevant as questions of schooling and civic education occupied a central place in Classical philosophy (cf. Heater 1990). Several of the liberal philosophers discussed here are typically inspired by the participatory virtues of republican thought while remaining true to fundamental liberal values such as individual freedom and tolerance.

In essence, monism is distinguished by a strong emphasis on citizenship and the reciprocal ties between citizens (see Paris 1991). Herein lies a strong commitment to democratic virtues and common public institutions. In diverse, capitalist societies, citizenship provides a secular egalitarian membership that provides a common identity for all members of society, regardless of race, class, gender or creed. Citizenship is a power vested in each and every citizen to ensure that people are ruled by themselves, rather than by the market or the church. This outlook inevitably relies on an unequivocal separation between private and public memberships.

For monists, the raison-d'être of schooling and civic education is to foster virtuous democratic citizens that will perpetuate and improve their society. Schools are supposed to be miniature melting pots where children learn to co-operate, overcome differences and relate to one another. The liberals of this quadrant believe that the reproduction of political virtues from one generation to the next requires a civic education that is thick in the ethical and the public dimension.

\section{Intra-Positional Engagement}

Key Issues A high-profile question for the monistic position is the common school. Monists are partial to these-some rather more unconditionally than others. The general reason is easily identifiable; the more diverse the population, the greater the need for integrative moulds (i.e., common schools) that mix children of different backgrounds and chip away the differences. Whether common schools actually succeed in this is a contested empirical question that is influenced by factors such as societal segregation, state funding, competition from private schools and much else (see Feinberg 2001). Still, ceteris paribus, monists are convinced that common and internally diverse schools constitute a workable remedy (Levinson 1997). The point can be restated in a more specific, egalitarian way that brings together integration and equality. Integration levels the playing field by blocking out private resources and affiliations from the public sphere. Common schools teach children that they are equals as political beings in ways that segregated schools cannot-or will not (see Callan 2001; Curren 2001; Feinberg 2001).

A second prominent issue is the rôle and place of civic education in schools. Monism, more than other liberal factions, stresses the value of what Martha Nussbaum (2006) has poetically labelled "political soul-making", by which she means an education that produces citizens and not just workers and consumers. Three values are especially important: Socratic self-criticism and critical thought; the ability to see oneself as a member of a heterogeneous nation; and narrative imagination, by which is meant the empathic ability to 
put oneself in someone else's shoes (ibid., p. 309). Similar arguments are advanced by Gutmann (1995) and Stephen Macedo (1995).

A less frequent monistic concern (but one that is possibly on the rise) is the challenge of educating a generation of environment-savvy citizens - a task that may require a special set of qualities and virtues (Postma 2002).

Internal Tensions Common to all monists is the notion that civic education should be ethically primed. There is less agreement what an ideal norm package should look like, however. Macedo (1995) wants to defend what he calls "liberalism with a spine", by which he means an education that puts a lot of effort into conveying explicit liberal values and civic qualities. Macedo claims to be a political liberal in the Rawlsian sense, and consequently any pushed values should be political, not personal or metaphysical. It is a form of civic education that urges children actively to engage in critical discussion and reflection on moral and religious diversity in order to stimulate public reason and tolerance, and discourages direct conflicts or criticism of personal beliefs (1995).

Macedo's "monism light" is criticised by people like Stephen Mulhall (1998) and Gutmann (1995) who claim that his distinction between what is political and what is comprehensive cannot be sustained. There is no way, they argue, to teach or exercise critical reason so that it is exclusively bound to political questions and conceptions of the good. Children who are taught these virtues will grow up to question and compare not only political but comprehensive conceptions of the good, and not only others' conceptions but their own and their parents' as well. This, Gutmann asserts, is a laudable process.

\section{Extra-Positional Engagement}

Monists oppose what is often described as a general tendency towards market orientation, functionalism and "civic illiteracy" (Nussbaum 2006). They oppose the excessive accommodation of diversity that characterises multiculturalism, as that is a road to fragmentation, segregation and inequalities. Children in liberal societies are educated for not just any future, but for a future as free, participating and democratic citizens. A state that allows parents to interdict that future for their children is a state that neglects its unbiased responsibility to all its citizens-to-be (Gutmann 1995). In this particular demurral, monists can join forces with universalist liberals. Even so, universalists are criticised for their obsession with neutrality and their futile attempts to insinuate, rather than indoctrinate, autonomy.

\section{The Universalist Position}

We have no right to look upon future citizens as if we were master gardeners who can tell the difference between a pernicious weed and a beautiful flower. A system of liberal education provides children with a sense of the very different lives that could be theirs-so that, as they approach maturity, they have the cultural materials available to build lives equal to their evolving conceptions of the good (Ackerman 1980, p. 139).

\section{General Overview of Articles and Themes}

Universalism could be described as the foremost defender of the Enlightenment legacy in liberal thought. It is rationalistic, individualistic and strongly committed to the value of 
freedom in the humane and emancipatory Kantian sense. It is distinguished by the attempt to find a common universal ground of human needs and goods, and by a continued resistance against moral relativism and particularism.

Universalists derive from Kant and Mill a strong emphasis on the value of autonomy. The purpose of the liberal state is to enable citizens to live autonomous lives. The state should, as far as possible, be a neutral enabler that refrains from promoting certain life projects over others. It should not be wholly neutral, however, but should encourage citizens to choose those projects themselves and of their own accord, rather than having them impressed by the church, the state or any other authority. A fundamental assumption is that all human beings share a capacity for critical reason and autonomous choice, and a defining assertion is that freedom means being able to exercise that capacity.

The purpose of universalist schooling and civic education is to provide children with an "open future", to use Feinbergs (1980) famous phrase. The "open future" project rests on two imperative conditions. First, schools need to teach children skills that support autonomous choice, e.g., critical rationality and self-reflection. Second, schools should expose children to the widest possible range of lifestyles, beliefs and worldviews that await them in society. In this sense, schools should, ideally, be like micro societies that emulate the real thing. Civic education should be ethically thin (i.e., non-indoctrinative) but publicly thick in order to promote an education for autonomy that is supported and defended by the liberal institutions of the state.

\section{Intra-Positional Engagement}

Key Issues A general but very important issue for universalists is whether or not civic education can be non-indoctrinative and legitimate. Brighouse (1998) poses the problem succinctly. The liberal state requires its citizens' licence, and the exercise of power in their name is only legitimate as long as their consent is freely given. Brighouse argues that a state that artificially inculcates certain virtues and values through the instrument of public schools is manufacturing consent, which by definition renders the state illegitimate. ${ }^{3}$ Brighouse's solution is that schools should "facilitate" the development of certain individual qualities, but abstain from directly "promoting" them (2001).

From this general principle spring a variety of standpoints. One view is that evenly dispersed diversity in schools is good because it facilitates encounters between children from different backgrounds. The key words here are "evenly dispersed", because as soon as student populations are split into majorities and minorities, or into diverse but internally homogeneous groups, opportunities for authentic encounters with diversity dwindle.

Another point is the "exposure model" of civic education, i.e., that civic pedagogy focuses on "neutral facts" about religion, politics, democracy, or whatever else is on the agenda. Getting to grips with facts about the world, about individual rights, about freedom of thought and so on is not just knowledge, but empowerment. It is a way to liberate children from the ignorance, narrow-mindedness and prejudice that would prevent them from choosing a life plan of their own (see Flathman 1996). This conception of civic education requires all major or relevant comprehensive views that an individual might hold to be represented, however. If this cannot be accomplished, civic education ceases to be neutral.

\footnotetext{
${ }_{3}$ A very similar argument is made by Mill (1998, p. 119), who is influential to Brighouse's way of reasoning in general.
} 
Internal Tensions The first point of friction has to do with the civic ends of neutral schooling. Education for autonomy is a case in point. Flathman (1996, p. 24) advances a strong position that is firmly grounded in the Millian conception of individuality and self-enactment. "Liberal education is regime nonspecific", and should have as its ambition to create politically literate and critical citizens who are "wary of politics and government" (ibid., pp. 24-26). A less demanding standpoint is that of Emile Lester (2006) whose specific aim is to narrow the gap between (what we label) multiculturalism and universalism with respect to autonomy. The purpose of an education for "moderate autonomy", he argues, is to create reasonable exit opportunities. By this he refers to awareness of alternative beliefs, freedom of religion and similar rights, but not to any explicit capacity for critical reason and choice. That is the non-reducible liberal baseline.

The second point of friction has to do with "neutral and representative exposure". What, to put it bluntly, is a justifiable method of selection? What is a relevant range of diversity? After all, schools cannot recognise and expose all forms of diversity that exist in the world. A European or North American school system may focus more on Western culture, even though this is ethnocentric. It may focus more on national history and politics, even though this may appear patriotic. It usually presupposes heterosexuality even though many children will grow up as bi- or homosexuals (see McDonough 2007). Relevance means selection, selection means bias. The tension stretches across a broad range of subjects and topics: sustainable development (Bell 2004); religion (Lester 2006); sexuality (McDonough 2007); and global citizenship (Schattle 2008).

Factual diversity in and between schools falls into a similar category. The reality of most urban areas is economic and cultural segregation, which means that most school environments will be significantly less diverse than society as a whole. If civic education presupposes the presence of difference, what is an adequate neutral response to school segregation? Brighouse (2001) explores the potential of a contested yet increasingly popular solution: vouchers. Vouchers may serve to increase social mobility between neighbourhoods and schools, but they may at the same time trigger relocation to private schools that offer non-neutral civics.

\section{Extra-Positional Engagement}

In A Theory of Justice (1971), John Rawls started out as what might be labelled a hardline universalist, then gradually softened his rationalist conception of autonomy to accommodate pluralist challenges (see Rawls 1985, 1987, 1993; cf. Johnston 2005). Many a universalist has followed in his footsteps. Multiculturalism is a "defining other", but three decades of antagonism have resulted in a gradual whittling down of the dichotomy to create a continuum of different positions between the two extremes. Universalists arguably have more in common with monists, but seem less willing to accommodate a thicker notion of civic education. Finally, it is a slippery slope between universalism and market liberalism. If state neutrality means non-interference and private freedom, why not let the market satisfy the demands of parents and children? Brighouse (2001) explores the potential and limits of this idea and seems ready to conclude that the state may legitimately privatise the execution of schooling, but not the content of and responsibility for it. Above all, the state must never reduce schooling to a mere fulfiller of market requirements. 


\section{Debate Patterns}

We will conclude this section by briefly describing the debate patterns quantitatively, and illustrate the results in a figure. First, we show the frequency of the different positions and inter-positional engagements. Second, we present a list of the most frequent engagement partners and cited authors. In the last section of the article, these patterns are discussed with respect to their impact on, and potential consequences for, the research field in some final remarks on the state of the debate.

\section{Positions and Engagements}

Studying Fig. 4 (below), two clarifying comments are in order. First, the size of the ellipses and the numbers within them indicate the salience of the positions in the material. As we can see, the debate is strongly tilted towards the right (publicly thick) end of the matrix. This is not much of a surprise, as support for active state involvement in schooling and for liberal ideals of citizenship is not a view that we really expect to find in the left end of the matrix. Still, one might expect more resistance to citizenship education and a stronger presence of alternative views of citizenship education than we have noted in the parsed articles-especially in the case of market liberalism that is a nearly invisible position in our material.

Second, the "engagement arrows" between the different positions depict the intensity and direction of inter-positional engagements. The thick arrows between different positions indicate what we might call "border conflicts", i.e., the defence and clarification of a position by means of criticism and distinction vis-à-vis opposing positions. As the figure shows, some border conflicts are more intense than others; some are unilateral and some bilateral. The arrows pointing at the two "Rawlsian style liberalism" boxes, finally, require

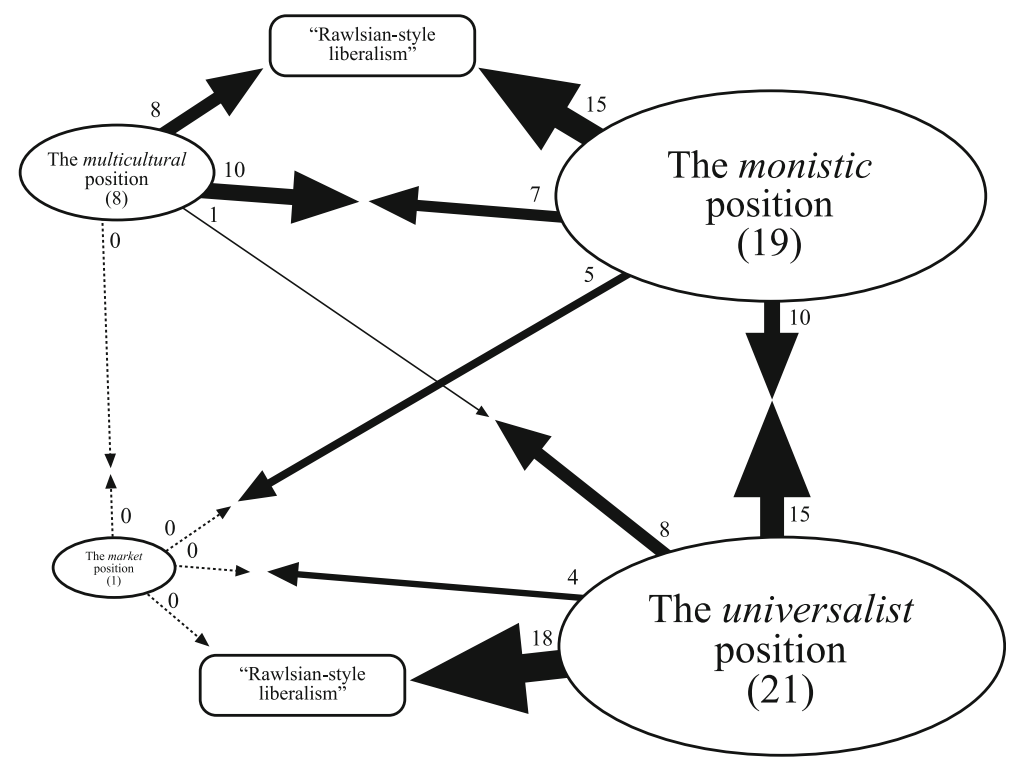

Fig. 4 Debate engagement patterns 
some elucidation. By "Rawlsian style liberalism" we mean a sort of middle-of-the-road position that is inspired, more or less explicitly, by Rawls's attempt to formulate a political-as opposed to comprehensive-liberal standpoint that is acceptable to as many people as possible. As we can see, this position is a standard point of reference for liberals of the three camps. We will discuss this more in the final section of the article.

\section{Sources of Inspiration}

To identify the principal sources of inspiration, as represented in our selected articles, we have carried out a two-pronged analysis of the material. In the qualitative leg, we take specific note of which thinkers, if any, a given author finds it particularly salient to engage with (whether to agree with or to denounce). To complement this of necessity qualitative evaluation, we then proceed to collect all formal references and-having controlled for self-references-see which authors generate most interest (Tables 1 and 2). Both tables confirm the previously hinted conclusion that "Rawlsian style liberalism" is a highly influential point of reference. In almost half of the articles (27 out of 55) Rawls is the prioritised engagement partner (Table 1) and his work appears in $2 / 3$ of all the reference lists of the parsed articles (Table 2). Below Rawls follow four scholars-Gutmann, Callan, Macedo and Galston-who have managed to create coherent and unambiguous liberal standpoints of their own, for which they are rewarded with a considerable number of citations, especially Gutmann. All save one (Macedo) openly reject the Rawlsian, middleof-the road, position.

Table 1 Top five prioritised engagement partners (as estimated by us) in 55 articles

\begin{tabular}{ll}
\hline $\begin{array}{l}\text { Referenced author } \\
\text { (all titles) }\end{array}$ & $\begin{array}{l}\text { Number of articles where author } \\
\text { is prioritised engagement partner (max 55) }\end{array}$ \\
\hline Rawls, John & 27 \\
Gutmann, Amy & 12 \\
Callan, Eamonn & 9 \\
Macedo, Stephen & 7 \\
Galston, William & 6 \\
\hline
\end{tabular}

Table 2 Top ten referenced authors (out of 1,230 references (minus self-references) in 55 articles)

\begin{tabular}{lll}
\hline $\begin{array}{l}\text { Referenced author } \\
\text { (all titles) }\end{array}$ & $\begin{array}{l}\text { Number of } \\
\text { references }\end{array}$ & $\begin{array}{l}\text { Referenced in } \\
\text { number of articles }\end{array}$ \\
\hline Rawls, John & $88(7.2 \%)$ & $37(67.3 \%)^{\mathrm{a}}$ \\
Gutmann, Amy & $54(4.4 \%)$ & $28(51.0 \%)$ \\
Macedo, Stephen & $38(3.1 \%)$ & $25(45.4 \%)$ \\
Galston, William & $34(2.8 \%)$ & $24(43.6 \%)$ \\
Callan, Eamonn & $27(2.2 \%)$ & $19(34.5 \%)$ \\
Kymlicka, Will & $22(1.8 \%)$ & $15(27.3 \%)$ \\
Brighouse, Harry & $19(1.5 \%)$ & $8(14.5 \%)$ \\
MacIntyre, Alasdair & $14(1.1 \%)$ & $13(23.6 \%)$ \\
Mill, John Stuart & $13(1.1 \%)$ & $12(21.8 \%)$ \\
Raz, Joseph & $13(1.1 \%)$ & $11(20.0 \%)$ \\
\hline
\end{tabular}

${ }^{a}$ A further 7 articles mention Rawls or "Rawlsian", but do not formally refer to his works in their reference lists. Added to the tally, $80 \%$ of the articles refer to Rawls

A further 7 articles mention
Rawls or "Rawlsian", but do not
formally refer to his works in
their reference lists. Added to the
tally, $80 \%$ of the articles refer to
Rawls




\section{State of the Debate: Concluding Remarks}

This is not primarily a longitudinal study, but the languid scholarly evolvement of the intersection between liberal theory and education policy is conspicuous enough to merit some discussion.

The evident importance in this field of John Rawls and his work is nothing short of remarkable. Of the 1,230 formal references, a full 88, spread across 37 (out of 55) articles, refer to his works, and attempt to concretise, revise, evolve or distance themselves from his ideas. A further 7 articles mention Rawls or "Rawlsian", but do not formally reference his works. His allure appears closely linked to his famous separation of political from comprehensive liberalism-polarities that translate well to an education-political context. That Rawls has in fact written very little about education per se (Johnston 2005, p. 203) even while his ideas seem so well matched to the field has understandably spurred many fine thinkers to address this shortcoming. The many complex points he brings to the table, and the creeping shifts within his corpus has attracted further interest-there is simply a great deal to discuss and make sense of. But if the star of Rawls's thinking has shed intriguing new light on the issue-area, it has also formed a gravity-well that it is clearly very hard to overcome, and that robs the discourse of momentum. Over the entire studied period, authors strain to build on or relate to rawlsian elements or offer viable alternatives, but very few (e.g., Gutmann, Macedo, Galston, maybe Callan) manage to attain escape velocity to establish complementing and generally recognised positions that will in turn help energise the debate. The fact that so many writers seem compelled to launch their efforts from a somewhat opaque rawlsian default position is, we think, a point worthy of further reflection.

A very much related concern is the amount of space devoted to state-of-the-debate introductions (which often amounts to the author's take on Rawls). The fact that this is so often deemed necessary underscores that we are dealing with a fragmented and far-flung discourse. In an admittedly complex issue-area, neither fragmentation, nor its far-flung characteristics need be detrimental of course, as it could mean steady concurrent advancements in many directions. Yet we suggest that there is cause to fear that the distribution of this particular discourse is such that it truly hampers its general progress. It is basically very hard to keep track of the amorphous debate in something even approaching its entirety. If our assessment is correct, this will by definition lead to redundancy and an inferior research situation. The sheer number of journals carrying salient material supports the notion that the debate is indeed very scattered, but on what grounds can one bear out concomitant fears?

In a truly contentious policy realm, it is notable how few authors actually manage to proceed all the way to applied advice and guidelines. Discussion tends to stay in the realm of abstract philosophy - and this is true even where titles indicate that real-world application is in the cards. Case in point: only a select few authors have anything concrete to say about civics even when that word is used explicitly in the title and in the text. More often than not it signals a concern with the relation between private and public; between state and parents; between diversity and schooling and between different school value foundations. Perfectly relevant topics all, but the gap between theory and practice must presumably be bridged at some point.

Though this is of course hard to corroborate, we feel that the persistent need to re-establish, and then marginally re-configure, the basic philosophical foundation is onerous enough to preclude - at least in article form-a "full" argument leading all the way from theoretical concerns to empirical suggestions. Given the spatial constraints of the 
journal article format (which obviously puts pressure on the ability to flesh out such "full" arguments, and which is something that may well merit separate consideration), is there any way to lessen the drag of the philosophical set-ups? Based on our study, we have argued that Rawls is too oblique, or, more generously, too multi-faceted to be the great unifier or clarifying point of reference of education-policy related thinking that his virtual omnipresence in the reviewed literature would perhaps otherwise suggest.

Now, before continuing we strongly emphasise that we do not suggest that the grappling with Rawls or the careful chiselling out of essential liberal ideals should be eschewed, far from it. Indeed, it was not until well into the study that we began to notice that such grappling (almost invariably taking place in individually stimulating and thought-provoking pieces) seemed somehow to crowd out other expected discourse elements—notably concretisation and normative nods to policy-makers.

We began this article with a framework identifying four archetypal liberal "positions". For all their flaws, these positions, like surely many other tenable conceptualisations, offer firmer (nb.: firmer, not better) ground than the ardently re-visited rawlsiana or deceptively bland yet contestable (and thus philosophically demanding) middle-of-the-road liberalism. A more effective way to triangulate the preferred, or indeed denounced, liberal-philosophical stance without being unavoidably bogged down by space-consuming minutiae would presumably free at least some authors to approach practical application. Using extreme liberal-philosophical outposts as beacons is just that: a simplified but effective method of positional triangulation. One such nascent beacon we have already touched upon is provided by Gutmann whose distinctive stance has caught the attention of a number of our studied authors-and as it happens these articles do indeed benefit a great deal from relating to her firm and unambiguous position. An advantage intrinsic to such an approach is that authors will be more likely to confront atavistic strands of liberal thinking that can be found in real-world political agitation. As we have shown, the market position-a theoretically viable quadrant in our model-appears largely overlooked or ignored in the reviewed articles, yet nevertheless thrives in certain political circles. If this discrepancy can be explained by the internal dynamics of the discourse itself, then we have to ask ourselves what else lies hidden in the recesses beyond the reach of a Rawls-centric debate.

Another scholarly fallacy, or virtue depending on your outlook, that perhaps co-explains the dearth of bullet-by-bullet policy advice, is a professional reluctance truly to embrace or endorse a specific position or theme. The disinterested weighing of alternatives is of course a prized and time-honoured norm in academia, but occasional strong recommendations are by their very nature significantly more likely to galvanise the discourse as well as appeal to extra-mural audiences. Launching this study, we had expected to encounter a wide range of truly "philosophical discourses"-and thus pieces that had no intention, or reason, to provide concrete advice-possibly clustered in specific journals (a title such as "Studies in Philosophy and Education", would seem to give the focus away). The surprise, to us, was that it would be so hard to locate tenaciously and unequivocally held opinions given the wide variety of journals. Is it that journal entries are consistently considered more intellectually robust if the author stays aloof whether or not s/he is in reality fencing for a specific team, pushing more animated entries to the book format? Or is it the fervid nature of the policy area itself that inspires unusual temperance in the academic community?

Whether or not this stylistic sobriety, and possibly attendant disinclination to pithily engage with policy-makers (and other scholars), constitutes a problem is not for us to evaluate. What we can say is that "bird's-eye studies" such as this one provide relevant input that is otherwise hard to come by if we want to study the rôle and reach of the journal medium itself (in a specified thematic field), and perhaps relate it to other research outlets. 
Open Access This article is distributed under the terms of the Creative Commons Attribution Noncommercial License which permits any noncommercial use, distribution, and reproduction in any medium, provided the original author(s) and source are credited.

\section{References}

\section{* = Parsed Article}

Ackerman, B. (1980). Social justice in the Liberal State. New Haven: Yale University Press.

*Archard, D. (1999). Should we teach patriotism? Studies in Philosophy and Education, 18, 157-173.

Barry, B. (2001). Culture and equality. Cambridge: Polity Press.

*Baumeister, A. (1998). Cultural diversity and education: The dilemma of political stability. Political Studies, 46(5), 919-936.

*Bell, D. (2004). Creating green citizens? Political liberalism and environmental education. Journal of Philosophy of Education, 38(1), 37-53.

*Brighouse, H. (1998). Civic education and liberal legitimacy. Ethics, 108(4), 719-745.

*Brighouse, H. (2001). Book symposium: Harry Brighouse, 'school choice and social justice'. Studies in Philosophy and Education, 20, 387-421.

Brighouse, H. (2002). School choice and social justice. Oxford: Oxford University Press.

*Brighouse, H. (2002). Egalitarian liberalism and justice in education. Political Quarterly, 73(2), 181-190.

*Bull, B. (2008). A politically liberal conception of civic education. Studies in Philosophy and Education, 27(6), 449-460.

*Callan, E. (2000). Liberal legitimacy, justice, and civic education. Ethics, 111(1), 141-155.

*Callan, E. (2001). Book symposium: Harry Brighouse, 'school choice and social justice'. Studies in Philosophy and Education, 20, 387-421.

Chubb, J., \& Moe, T. (1990). Politics, markets, and America's schools. Washington, DC: Brookings.

*Coleman, J. (1998). Civic pedagogies and liberal-democratic curricula. Ethics, 108(4), 746-761.

*Costa, V. (2004). Rawlsian civic education: Political not minimal. Journal of Applied Philosophy, 21(1), $1-14$.

*Curren, R. (2001). Book symposium: Harry Brighouse, 'school choice and social justice'. Studies in Philosophy and Education, 20, 387-421.

Dagger, R. (1997). Civic virtues: Rights, citizenship, and the republican liberalism. Oxford: Oxford University Press.

*Dagovitz, A. (2004). When choice does not matter: Political liberalism, religion and the faith school debate. Journal of Philosophy of Education, 38(2), 167-180.

*Davis, G., \& Neufeld, B. (2007). Political liberalism, civic education, and educational choice. Social Theory and Practice, 33(1), 47-74.

*Duck-Joo, K. (2004). Reconsideration of Rorty's view of the liberal ironist and its implications for postmodern civic education. Educational Philosophy and Theory, 36(4), 347-359.

*Enslin, P. (2001). Multicultural education, gender and social justice: Liberal feminist misgivings. International Journal of Educational Research, 35, 281-292.

Feinberg, J. (1980). A child's right to an open future. In W. Aiken \& H. LaFollette (Eds.), Whose child?. Totowa, NJ: Littlefield, Adams.

*Feinberg, W. (2001). Book symposium: Harry Brighouse, 'school choice and social justice'. Studies in Philosophy and Education, 20, 387-421.

*Ferrero, D. (2004). Fresh perspectives on school choice. Journal of Philosophy of Education, 38(2), 287-296.

*Finlay, G. (2007). Comprehensive liberalism and civic education in the Republic of Ireland. Irish Political Studies, 22(4), 473-493.

*Flathman, R. (1996). Liberal versus civic, republican, democratic and other vocational educations: Liberalism and institutionalized education. Political Theory, 24(1), 4-32.

Galston, W. (1991). Liberal purposes: Goods, virtues, and diversity in the liberal state. Cambridge: Cambridge University Press.

Galston, W. (1995). Two concepts of liberalism. Ethics, 105(3), 516-534.

*Galston, W. (2006). Signs of progress. The debate over civic education. Theory and Research in Education, 4(3), 329-337.

*Gutmann, A. (1995). Civic education and social diversity. Ethics, 105(3), 557-579. 
Gutmann, A. (1999). Democratic education. Princeton: Princeton University Press.

*Halliday, J. (1999). Political liberalism and citizenship education: Towards curriculum reform. British Journal of Educational Studies, 47(1), 43-55.

*Halliday, J. (2001). Reason, education and liberalism: Family resemblance within an overlapping consensus. Studies in Philosophy and Education, 20(3), 225-234.

Heater, D. (1990). Citizenship: The civic ideal in world history, politics and education. London: Longman.

*Hostetler, K. (1998). Towards a perfectionist response to ethical conflict. Studies in Philosophy and Education, 17, 295-302.

*Jo, A. (2008). Learning or earning in the 'smart state': Changing tactics for governing early childhood. Childhood (Copenhagen), 15(4), 535-551.

*Johnston, J. (2005). Rawls's kantian educational theory. Educational Theory, 55(2), 200-218.

Kymlicka, W. (1995). Multicultural citizenship: A liberal theory of minority rights. Oxford: Oxford University Press.

*Lecce, S. (2008). How political is the personal? Justice in upbringing. Theory and Research in Education, 6(1), 21-45.

*Lester, E. (2006). The right to reasonable exit and a religious education for moderate autonomy. The Review of Politics, 68, 612-635.

*Levinson, M. (1997). Liberalism versus democracy? Schooling private citizens in the public square. British Journal of Political Science, 27(3), 333-360.

*Levinson, M. (1999). Liberalism, Pluralism, and Political Education: Paradox or Paradigm? Oxford Review of Education, 25(1-2), 39-58.

Macedo, S. (1995). Liberal civic education and religious fundamentalism: The case of God v. John Rawls? Ethics, 105(3), 468-496.

Macedo, S. (2000). Diversity and distrust: Civic education in a multicultural democracy. Cambridge, MA: Harvard University Press.

Margalit, A., \& Halbertal, M. (1994). Liberalism and the right to culture. Social Research, 61(3), 491-510.

*McCabe, D. (1995). Liberal education is moral education. Social Theory and Practice, 21(1), 83-96.

*McDonough, K. (1998). Can the liberal state support cultural identity schools? American Journal of Education, 106(4), 463-469.

*McDonough, K. (2007). The 'futures' of queer children and the common school ideal. Journal of Philosophy of Education, 41(4), 795-810.

Mill, J. (1998/1859). On liberty. In On liberty and other essays. Oxford: Oxford University Press.

*Mulhall, S. (1998). Political liberalism and civic education: The liberal state and its future citizens. Journal of Philosophy of Education, 2, 161-176.

*Nussbaum, M. (2006). Political soul-making and the imminent demise of liberal education. Journal of Social Philosophy, 37(2), 301-313.

Oakley, A., Gough, D., Oliver, S., \& Thomas, J. (2005). The politics of evidence and methodology: lessons from the EPPI-centre. Evidence and Policy: A Journal of Research, Debate and Practice, 1(1), 5-31.

*O'Leary Goldwyn, C. (2005). Schooling for citizenship. Bridging autonomy and conflict. Political Theory, 33(5), 721-726.

*Papastephanou, M. (2005). Rawls' theory of justice and citizenship education. Journal of Philosophy of Education, 39(3), 499-518.

*Paris, D. (1991). Moral education and the 'tie that binds' in liberal political theory. The American Political Science Review, 85(3), 875-901.

Pettit, P. (1997). Republicanism: A theory of freedom and government. Oxford: Clarendon Press.

*Postma, D. (2002). Taking the future seriously: On the inadequacies of the framework of liberalism for environmental education. Journal of Philosophy of Education, 36(1), 41-56.

*Pybas, K. (2004). Liberalism and civic education: Unitary versus pluralist alternatives. Perspectives on Political Science, 33(1), 18-29.

Rawls, J. (1971). A theory of justice. Cambridge, MA: Harvard University Press.

Rawls, J. (1985). Justice as fairness: Political not metaphysical. Philosophy and Public Affairs, 14(Summer), 223-239.

Rawls, J. (1987). The idea of an overlapping consensus. Oxford Journal of Legal Studies, 7(1), 1-25.

Rawls, J. (1993). Political liberalism. New York: Columbia University Press.

*Rhoads, R., \& Calderone, S. (2007). Reconstituting the democratic subject: Sexuality, schooling, and citizenship. Educational Theory, 57(1), 105-121.

*Ruderman, R., \& Godwin, R. (2000). Liberalism and parental control of education. Review of Politics, $62(3), 503-529$.

*Schattle, H. (2008). Education for global citizenship: Illustrations of ideological pluralism and adaptation. Journal of Political Ideologies, 13(1), 73-94. 
*Singh, B. (1998). Liberalism, parental rights, pupils' autonomy and education. Educational Studies, 24(2), 165-182.

*Steutel, J., \& Spiecker, B. (1999). Family education, state intervention and political liberalism. Journal of Philosophy of Education, 33(3), 371-386.

*Strike, K. (1998a). Freedom of conscience and illiberal socialization: The congruence argument. Journal of Philosophy of Education, 32(3), 345-360.

*Strike, K. (1998b). Liberalism, citizenship, and the private interest in schooling. Studies in Philosophy and Education, 17, 221-229.

*Topping, R. (2008). St. Augustine, liberalism, and the defence of liberal education. New Blackfriars, 89(1024), 674-690.

van Gunsteren, H. (1998). A theory of citizenship. Boulder, Colorado: Westview Press.

*Wallach, J. (2000). Can liberalism be virtuous? Polity, 33(1), 163-174.

*Weinstein, J. (2004). Neutrality, pluralism, and education: Civic education as learning about the other. Studies in Philosophy and Education, 23, 235-263.

*White, L. (2003). Liberalism, group rights and the boundaries of toleration: The case of minority religious schools in ontario. Canadian Journal of Political Science, 36(5), 975-1003.

*Wingo, A. (1997). Civic education: A new proposal. Studies in Philosophy and Education, 16, $277-291$.

*Wolfe, C. (2001). Offensive liberalism. Review of Politics, 63(2), 377-380.

*Yossi, Y., Yossi, D., \& Markovich, D. (2008). Neo-liberal reforms in Israel's education system: The dialectics of the state. International Studies in Sociology of Education, 18(3-4), 199-217. 